\title{
A novel mutation in GPD1-L associated with early repolarization syndrome via modulation of cardiomyocyte fast sodium currents
}

\author{
JUN FAN $^{1,2^{*}}$, CHENG-CHENG JI ${ }^{1,2^{*}}$, YUN-JIU CHENG ${ }^{1 *}$, HAO YAO $^{1,2}$, \\ XU-MIAO $\mathrm{CHEN}^{1}$, ZI-HENG $\mathrm{ZHENG}^{1}$ and SU-HUA WU ${ }^{1,2}$ \\ ${ }^{1}$ Department of Cardiology, The First Affiliated Hospital, Sun Yat-sen University; \\ ${ }^{2}$ NHC Key Laboratory of Assisted Circulation, Guangzhou, Guangdong 510080, P.R. China
}

Received June 6, 2019; Accepted October 31, 2019

DOI: $10.3892 /$ ijmm.2020.4454

\begin{abstract}
Early repolarization syndrome (ERS) is associated with genetic mutations, but the role of the glycerol-3-phosphate dehydrogenase 1-like (GPD1-L) mutation remains unclear. The aim of the present study was to investigate the role and potential underlying mechanism of GPD1-L mutation P112L in the pathogenesis of ERS. Whole-genome sequencing was performed on samples from a family with ERS, and the gene sequencing results were analyzed using bioinformatics. 293 cells were transfected with wild-type (WT) or mutant-type (MT) GPD1-L and SCN5A plasmids. Successful transfection of GPD1-L in 293 cells was verified by western blotting. Whole-cell patch-clamp recording, confocal microscopic observation and western blotting were used to uncover the potential mechanism of GPD1-L P112L in ERS. The results of western blotting indicated that the expression of the GPD1-L protein was lower in the MT group compared with that in the WT group, but the mock group did not express the GPD1-L protein. The whole-cell patch-clamp recording results indicated that the activation current density of $\mathrm{I}_{\mathrm{Na}}(\mathrm{at}-30 \mathrm{mV})$ was $\sim 60 \%$ lower in the MT group compared with the WT group $(\mathrm{P}<0.01)$. The mutation caused the inactivation voltage to move in a negative direction by $\sim 3 \mathrm{mV}$ compared with that of the WT group. However, there were no significant between-group differences in the steady activation, steady inactivation, and steady recovery of $\mathrm{I}_{\mathrm{Na}}$. Confocal microscopy demonstrated that MT GPD1-L was less expressed near the cell membrane and more expressed in the cytoplasm compared with WT GPD1-L. Both WT and MT GPD1-L were highly expressed in the cytoplasm and in small amounts in the nucleus. In conclusion, the
\end{abstract}

Correspondence to: Dr Su-Hua Wu, Department of Cardiology, The First Affiliated Hospital, Sun Yat-Sen University, Building 5, 58 Zhongshan Road II, Guangzhou, Guangdong 510080, P.R. China E-mail:wusuhua@hotmail.com

*Contributed equally

Key words: early repolarization syndrome, genetic mutation, glycerol-3-phosphate dehydrogenase 1-like, whole-cell patch-clamp
GPD1-L P112L mutation decreased $\mathrm{I}_{\mathrm{Na}}$ activation and GPD1-L cell expression, including in the region near the cell membrane. These results suggest that GPD1-L P112L may be a pathogenic genetic mutation associated with ERS.

\section{Introduction}

Unexplained cardiac death is mainly caused by malignant ventricular tachycardia, ventricular fibrillation, or both (1). On electrocardiography, an early repolarization pattern (ERP) appears to be common among cardiac death cases (2). ERP is characterized by J point (QRS-ST junction) elevation of $>0.1 \mathrm{mV}$ in at least two leads on the electrocardiogram, accompanied by J-wave slurring and notching changes (3). Patients with an ERP and unexplained cardiac arrest, but without structural heart disease, have early repolarization syndrome (ERS) (4).

ERPs are common among the relatives of patients with ERS. Therefore, heredity of a genetic mutation may play a key role in the occurrence of ERPs (5). The main mechanism of ERP is disordered ion currents during the depolarization stage and during the early stages of repolarization of cardiomyocyte action potentials (6). These abnormal ion currents mainly include transient outward potassium currents (7), fast sodium currents (8), inward-rectifier ATP-dependent $\mathrm{K}^{+}$channel currents (9), and L-type calcium currents (10). Study results suggest that the 'loss of function' caused by mutations of CACNA1C (11), CACNB2b (12), CACNA2D1 (12), SCN5A (8) and SCN10A (13), and 'gain of function' caused by mutations of KCNJ8 (14) and ABCC9 (15), are associated with ERS.

The glycerol-3-phosphate dehydrogenase 1-like (GPD1-L) gene is located on chromosome 3. GPD1-L is mainly expressed near, but not on the cell membrane (16), and it may affect the action potentials of cardiomyocytes via regulation of sodium channel function (16). The objective of the present study was to examine the effects of changes in GPD1-L using co-expression of GPD1-L with Nav1.5 in 293 cells in order to determine whether there is an association between ERS and of a loss of function in $\mathrm{I}_{\mathrm{Na}}$ secondary to mutations in GPD1-L.

\section{Materials and methods}

Ethics approval. The present study was performed in accordance with the principles for ethical human genetic disease 
research formulated by the World Medical Association and the Helsinki Declaration. The investigation was approved by the Ethics Committee of the First Affiliated hospital of Sun Yat-Sen University. All family members agreed to participate in the study and signed the informed consent forms.

Clinical study. Patients with ERS admitted to the First Affiliated Hospital of Sun Yat-Sen University in 2015 were selected for the study. All clinical data, including those obtained from records of routine and specialized cardiovascular disease examinations (electrocardiogram, Holter electrocardiogram, $\mathrm{X}$-ray, echocardiography, coronary angiography, and electrophysiological examination) were collected. ERP was defined as J point (QRS-ST junction) elevation of $>0.1 \mathrm{mV}$ on the electrocardiogram, in at least two leads, accompanied by J-wave slurring or notching changes. Detailed family histories of the probands were investigated, and the family pedigrees were drawn. Full and reliable clinical phenotype data were collected as well as possible. Peripheral venous blood was extracted from each proband for genetic testing.

Genetic sequencing and analysis. QIAamp DNAKits (Qiagen $\mathrm{GmbH}$ ) were used to extract blood DNA according to the standard operating manual method recommended by the manufacturer. The samples used to build the libraries met the requirements for new-generation high-throughput gene sequencing. Whole-genome sequencing was performed using Next Generation Sequencing and the HiSeq X Ten (Illumina, Inc.).

The reference sequences were compared with the sequencing results. Bioinformatics methods were used to detect and annotate single-nucleotide variants (SNVs) and InDel results. The gene frequency of each SNV was determined using comparison with standard databases (e.g., the 1000 Genomes Project and dbSNP). Candidate genes for malignant arrhythmias have been described previously (17). SNVs with allele frequencies $<1 \%$ were selected during screening to facilitate further investigation and identification of sudden death-related genes. Protein function prediction software [PROVEAN Protein, version 1.1 (http://provean.jcvi.org/seq submit.php) and SIFT, version 6.2.1 (http://sift.bii.a-star.edu. $\mathrm{sg} /)]$ and conservation of gene sequences analysis software [PhyloP (https://ccg.epfl.ch//mga/hg19/phylop/phylop.html) and Grantham (https://gist.github.com/danielecook/501f0365 0bca6a3db31ff3af2d413d2a)] were used to predict the protein functions encoded by the mutant genes. The candidate genetic mutation present in each proband was verified using Sanger sequencing.

Mutagenesis, cell culture and transfection. Nav1.5 cDNA (SCN5A, NM_198056) was subcloned into the mammalian expression vector, pENTER. For western blotting and electrophysiological study, GPD1-L cDNA (NM_015141.3) was amplified using PCR and subcloned into pIRES2-EGFP. When the plasmid was transfected into 293 cells, the 293 cells expressed enhanced green fluorescent protein (eGFP) and GPD1-L protein. For the confocal microscopy examination, GPD1-L cDNA (NM_015141.3) was amplified using PCR and subcloned into pEGFP-N1. When the plasmid was transfected into 293 cells, the 293 cells expressed eGFT-GPD1-L fusion protein to trace the trafficking of GPD1-L. The p. P112L mutation of GPD1-L was introduced by site-directed mutagenesis using the QuikChange II kit (Stratagene; Agilent Technologies, Inc.). 293 cells were cultured in DMEM containing 10\% fetal bovine serum, and under the conditions of $5 \% \mathrm{CO}_{2}$ and $37^{\circ} \mathrm{C}$. 293 cells were transfected with SCN5A plasmid and WT/MT GPD1-L plasmid (1:1 molar ratio) using Lipofectamine 3000 transfection reagent (Invitrogen; Thermo Fisher Scientific, Inc.). The electrophysiological recordings, western blotting, and confocal microscopy observations were performed according to the manufacturers' instructions.

Western blotting. After transfection for $24 \mathrm{~h}$, the medium was discarded and the cells were washed twice using pre-cooled PBS; $120 \mu 1$ ice-cold RIPA buffer (Beyotime Institute of Biotechnology) was added to each well of 6-well plates, and the plates were shaken on ice for $15 \mathrm{~min}$. Intermittent ultrasound $(200 \mathrm{~W}, 25 \%$ power) was used to lyse the cells (working for $3 \mathrm{sec}$ and stopping for $5 \mathrm{sec}$ ), until the lysates were clear and bright. After centrifugation at $12,580 \mathrm{xg}$ for $15 \mathrm{~min}$ at $4^{\circ} \mathrm{C}$, the supernatant was collected as the protein sample.

The protein samples were quantified using the BCA Protein Quantitation kit (Thermo Fisher Scientific, Inc.) according to the manufacturer's instructions. Each protein sample was diluted using $5 \mathrm{X}$ loading buffer and was denatured in $95^{\circ} \mathrm{C}$ water for $10 \mathrm{~min}$. Protein samples $(10 \mu \mathrm{g} / \mathrm{lane})$ were separated by $10 \%$ SDS-PAGE gel and transferred to PDVF membranes. The PVDF membranes were blocked using 5\% BSA solution (Thermo Fisher Scientific, Inc.) and incubated with anti-GPD1L antibody (1:500, cat. no. NPB1-32279, Novus Biologicals, Ltd.) and anti-tubulin antibody (1:5,000, cat. no. 66031-1-Ig, Proteintech Group, Inc.) overnight on a shaker at $4^{\circ} \mathrm{C}$. The PVDF membranes were washed four times (10 min each time) using TBS/0.1\% Tween-20 (TBST) solution and were incubated with HRP-conjugated goat-anti-mouse secondary antibody $(1: 10,000$, cat. no. 15134-1-AP, Proteintech Group, Inc.) for $1 \mathrm{~h}$ at room temperature. After the secondary antibody incubation, the PBST solution was used to wash the membranes four times (10 min each time). The proteins were visualized using enhanced chemiluminescence on an X-ray film in a dark room. The results were quantified using Image J software, version 1.52a (National Institutes of Health). For the analysis, the GPD1-L blots were standardized to the corresponding tubulin blots in each sample.

Electrophysiological recordings. Electrophysiological recordings were performed using a microelectrode manipulator (MP285, Sutter Instruments) under an inverted microscope (IX71, Olympus Corporation). The recording electrodes were prepared from capillary glass tubes (BF150-86-10, Sutter Instruments), which were modified using three steps and a microelectrode puller (P97, Sutter Instruments). The patch pipette resistance was 2-3 M $\Omega$ when filled with pipette solution. The bath solution contained $140 \mathrm{mM} \mathrm{NaCl}, 4 \mathrm{mM} \mathrm{KCl}$, $1 \mathrm{mM} \mathrm{MgCl} 2,2 \mathrm{mM} \mathrm{CaCl}, 5 \mathrm{mM}$ D-glucose monohydrate, and $10 \mathrm{mM}$ HEPES (pH 7.4, adjusted using $\mathrm{NaOH}$ ). The pipette solution contained $145 \mathrm{mM} \mathrm{CsCl}, 0.1 \mathrm{mM} \mathrm{CaCl}_{2}$, $2 \mathrm{mM} \mathrm{MgCl}_{2}, 10 \mathrm{mM} \mathrm{NaCl}, 0.5 \mathrm{mM} \mathrm{Na}_{2}-\mathrm{GTP}, 2 \mathrm{mM} \mathrm{Mg}$-ATP, $1.1 \mathrm{mM}$ EGTA, and $10 \mathrm{mM}$ HEPES (pH 7.2, adjusted using $\mathrm{CsOH})$. After the patch pipette contacted the cell membrane, 
Table I. Electrocardiographic characteristics of the patient's family members.

\begin{tabular}{lcccccccc}
\hline ID & Sex & $\begin{array}{c}\text { Age } \\
(\text { years })\end{array}$ & HR (bpm) & $\begin{array}{c}\text { J-wave } \\
\text { location }\end{array}$ & $\begin{array}{c}\text { J-wave } \\
\text { amplitude (mV) }\end{array}$ & $\begin{array}{c}\text { ST } \\
\text { elevation }(\mathrm{mV})\end{array}$ & $\begin{array}{c}\text { QRS } \\
\text { R (mV) }\end{array}$ & $\begin{array}{c}\text { QTc } \\
(\mathrm{msec})\end{array}$ \\
\hline I.1 & M & 66 & 88 & II, III, aVF V4-V6 & 0.30 & 0.05 & 1.40 & 100 \\
II.1 & M & 36 & 68 & - & - & 0 & 388 \\
II.2 & M & 34 & 65 & II, III, aVF & 0.20 & 0 & 0.10 & 80 \\
II.3 & F & 29 & 71 & - & - & 0 & 426 \\
\hline
\end{tabular}

HR, heart rate; bpm, beats per min; M, male; F, female.

negative pressure was used to form a $G \Omega$ seal and break the cell membrane to create the whole-cell recording mode. All electrophysiological experiments were performed at room temperature. Currents were filtered and digitized using default settings. Series resistance $(80 \%)$ was compensated by computer. The data were collected using an EPC-10 amplifier (HEKA Elektronik) and stored in PatchMaster software, version 2x90.5 (HEKA Elektronik). The results were analyzed using PatchMaster and IGOR Pro 6.0 software.

The activation $\mathrm{I}_{\mathrm{Na}}$ values were measured by providing cell pulsing voltages ranging from -120 to $30 \mathrm{mV}(10-\mathrm{mV}$ step pulse), with a holding potential at $-120 \mathrm{mV}$; the peak $\mathrm{I}_{\mathrm{Na}}$ value was also recorded. The peak current was fitted using the Boltzmann function: $\mathrm{G}_{\mathrm{Na}} / \mathrm{G}_{\max }=\left[1+\exp \left(\mathrm{V}_{1 / 2}-\mathrm{V}_{\mathrm{c}}\right) / \mathrm{k}\right]^{-1}$, where $\mathrm{k}$ is the slope factor and $\mathrm{V}_{1 / 2}$ is the half-maximal voltage of activation. $\mathrm{G}_{\mathrm{Na}}=\mathrm{I}_{\mathrm{Na}} /\left(\mathrm{V}-\mathrm{V}_{\text {rev }}\right)$, where $\mathrm{V}$ is the membrane potential and $\mathrm{V}_{\text {rev }}$ is the reversal potential. The inactivation $\mathrm{I}_{\mathrm{Na}}$ values were measured using a two-step protocol, with a holding potential at $-120 \mathrm{mV}$. The first step was a $30-\mathrm{msec}$ conditional pulse; the voltage range was from -120 to $-20 \mathrm{mV}(10-\mathrm{mV}$ step pulse). The second step was the test pulse $(-20 \mathrm{mV})$, and the peak sodium current was recorded. The current was fitted using the Boltzmann function: $\mathrm{I} / \mathrm{I}_{\max }=\left[1+\exp \left(\mathrm{V}_{\mathrm{c}}-\mathrm{V}_{1 / 2}\right) / \mathrm{k}\right]^{-1}$, where $\mathrm{V}_{\mathrm{c}}$ is the membrane potential. The recovery $\mathrm{I}_{\mathrm{Na}}$ values were measured using a three-step protocol, with a holding potential at $-120 \mathrm{mV}$. The duration $(30 \mathrm{msec})$ and voltage $(-20 \mathrm{mV})$ of the condition pulse and test pulse amplitudes were consistent, and the two pulses were spaced from 1 to $60 \mathrm{msec}$, in 1-msec steps. The values for the peak currents induced by the test pulses were recorded. The current was fitted using an exponential function: $\mathrm{I} / \mathrm{I}_{\max }=\mathrm{A}+\mathrm{A} 1^{*} \exp (-\mathrm{t} / \mathrm{t})$, where $\mathrm{t}$ stands for time and $t$ is the recovery time constant. All data were plotted using Origin 8 software (OriginLab CorporationA).

Immunofluorescence and confocal microscopy. All treated 293 cells expressing eGFP-GPD1-L fusion protein were imaged at room temperature using a Zeiss LSM 780 confocal system with ZEN software (black edition, version 11.0.0190). The images were acquired using a x63 oil immersion objective and X10 ocular lens.

After the 293 cells were transfected with the plasmid for $48 \mathrm{~h}$, they were digested using $0.25 \%$ trypsin (2520056, Gibco; Thermo Fisher Scientific, Inc.), resuspended, and attached to tissue culture-treated confocal dishes (BDD012035, Jet Biofil). Cell membranes were stained using 1,1'-dioctadecyl-3,3,3',3'-tetramethylindocarbocyanine perchlorate (Dil;
$3 \mu \mathrm{M}$, D4010, US Everbright, Inc.) for $5 \mathrm{~min}$ at $37^{\circ} \mathrm{C}$. The cells were then fixed using $4 \%$ paraformaldehyde for $15 \mathrm{~min}$ at room temperature. DAPI ( $1 \mu \mathrm{g} / \mathrm{ml}$, D4054, US Everbright, Inc.) was then added. The cells were then exposed to a Dil excitation wavelength of $549 \mathrm{~nm}$, and emission sections were collected between 560 and $580 \mathrm{~nm}$. The EGFP-GPD1-L fusion protein excitation wavelength was $488 \mathrm{~nm}$, and emission sections were collected between 505 and $530 \mathrm{~nm}$. The DAPI excitation wavelength was $360 \mathrm{~nm}$, and emission sections were collected at $460 \mathrm{~nm}$.

Statistical analysis. The data were analyzed using an SPSS 20.0 software package (IBM Corp.) and the results were expressed as mean \pm standard deviation values. Student's t-tests were used for between-group comparisons. One-way ANOVA and Student-Newman-Keuls tests were used for comparisons of multiple groups. $\mathrm{P}<0.01$ was considered to indicate a statistically significant difference.

\section{Results}

Clinical data. A family whose electrocardiograms showed ERP from January 2013 to June 2015 was investigated. The mean age of the patients was 50 years (standard deviation, 22.62 years). The details of the family members are presented in Table I. Blood samples were collected from the proband (black arrow) for whole-genome sequencing analysis. The whole-genome sequencing and bioinformatics analysis of the proband genomic DNA revealed a total of 22,205 missense SNV sites in the exon regions. After screening for candidate genes for malignant arrhythmias, allele frequencies $<1 \%$ and protein function prediction, GPD1-L was identified as the suspected pathogenic mutation (NCBI Reference Sequence: rs1201810677, https:/www.ncbi.nlm.nih. gov/snp/rs1201810677). The results for the mutation sites of the GPD1-L gene are presented in Fig. 1B. The mutation in the proband was verified using Sanger sequencing (Fig. 1C). This mutation resulted in the conversion of a hydrophilic proline to a hydrophobic leucine at position 112 of the GPD1-L protein.

The proband was a 34-year-old man who suffered from recurrent palpitations with dizziness, fatigue and amaurosis fugax. The patient's electrocardiogram results are presented in Fig. 1D. The electrocardiogram revealed J-point elevations $(>0.1 \mathrm{mV})$ in leads II, III and aVF, and a slurring $\mathrm{J}$ wave. The chest X-ray, echocardiography, serum electrolyte levels, coronary angiography, multiple myocardial enzyme tests and 
A

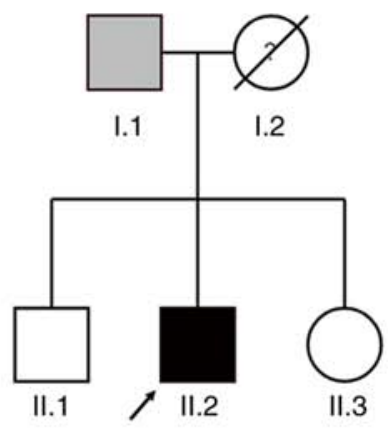

B

WT

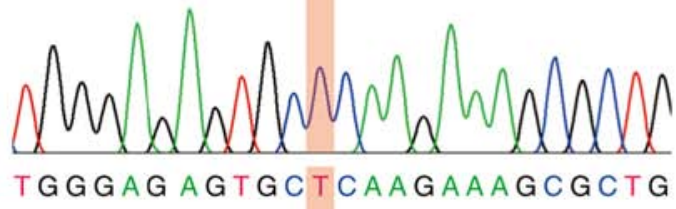

MT

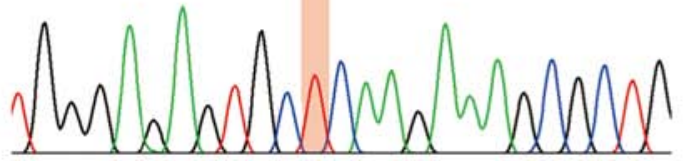

C $T G A G A T C A C T G G G A G A G T G C \subset C A A G A A A G C G C T G G G A A T C A C$

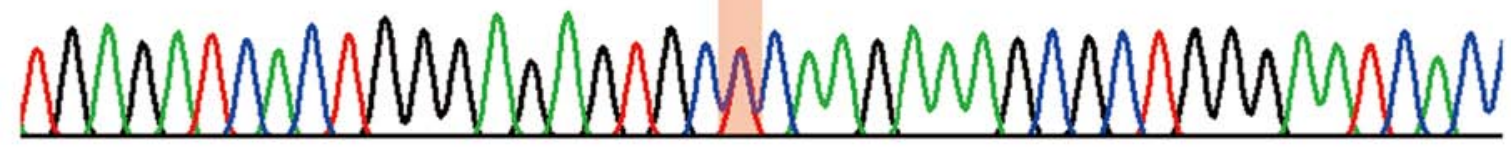

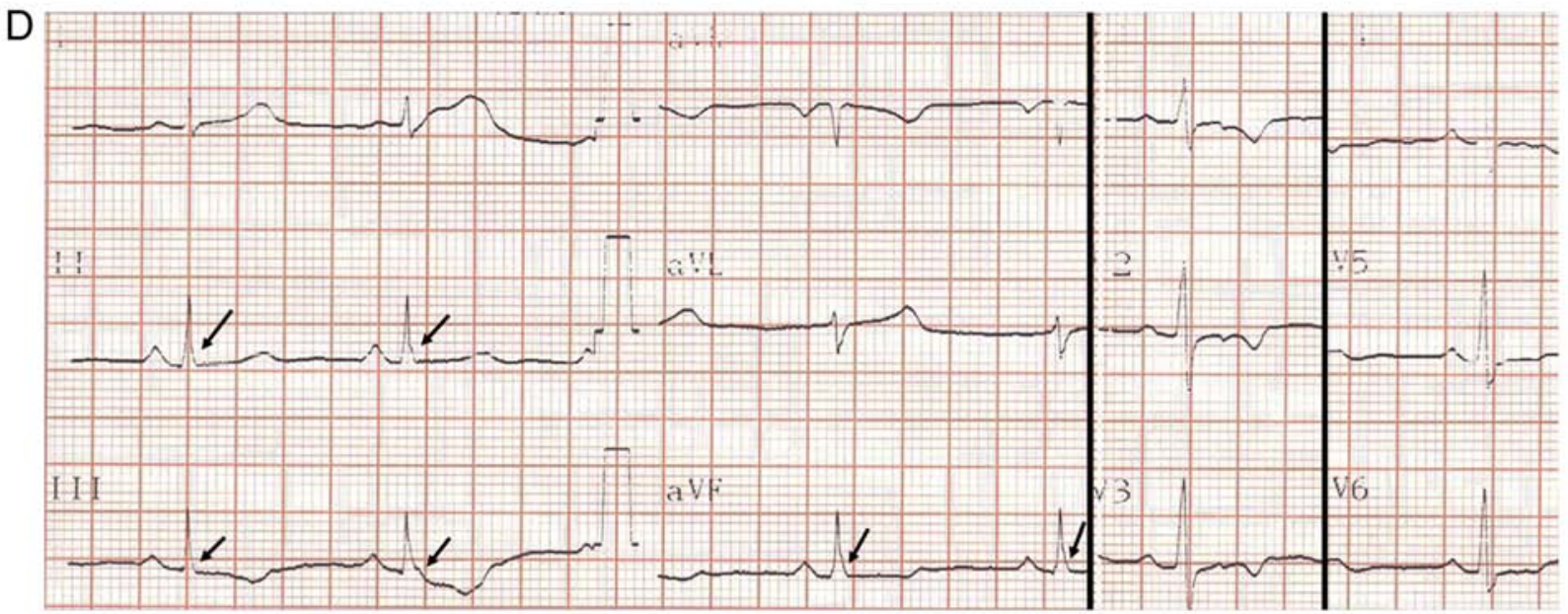

Figure 1. Clinical data of family members with ERS. (A) Family pedigree of ERS syndrome (arrow, proband). Gray square, presence of an ERP without sudden cardiac death; black square, presence of an ERP with concurrent malignant ventricular arrhythmia. (B) Proband DNA sequence of GPD1-L exon showing $\mathrm{C}>\mathrm{T}$ substitution generating a proline (P) to lysine (L) at residue 112 of GPD1-L. (C) Partial sequencing sequences containing P112L mutations. (D) Electrocardiogram of the proband exhibits J-point elevation $(>0.1 \mathrm{mV})$ in leads II, III and aVF, and a slurring J wave (arrows). ERS, early repolarization syndrome; ERP, early repolarization pattern; GPD1-L, glycerol-3-phosphate dehydrogenase 1-like; WT, wild-type; MT, mutant type.

treadmill test results were within the reference ranges. The results of the patient's electrocardiogram monitoring indicated the presence of ventricular premature contractions and short polymorphic ventricular tachycardia. Based on these results, ERS was diagnosed in the proband. A clinical investigation of all members of the family (brother, sister and both parents of the proband) revealed that the father's electrocardiography results indicated the presence of ERPs, but the siblings' electrocardiograms did not.

GPD1-L was successfully transfected in 293 cells and P112L mutant decreased the expression of GPD1-L. Western blotting of whole-cell lysates was performed to verify the successful transfection of GPD1-L and study the effects of gene mutation on protein expression. Tubulin, with a molecular weight of $55 \mathrm{kDa}$, was used as an internal reference protein. The results indicated that both the WT and MT groups expressed the GPD1-L protein, but the mock group did not (Fig. 2A), which suggested that GPD1-L was successfully transfected in 293 cells. The expression level of MT-GPD-1L was significantly reduced in the MT group compared with the WT group $(\mathrm{P}<0.01$; Fig. 2B).

P112L mutation decreased $I_{N a}$ activation. 293 cells were transfected with both SCN5A plasmid and WT/MT GPD1-L plasmid. The results for representative activation of $\mathrm{I}_{\mathrm{Na}}$ in the 293 cells of the WT and MT groups are presented in Fig. 3A. The voltage stimulation protocol for activation of $\mathrm{I}_{\mathrm{Na}}$ is 
A

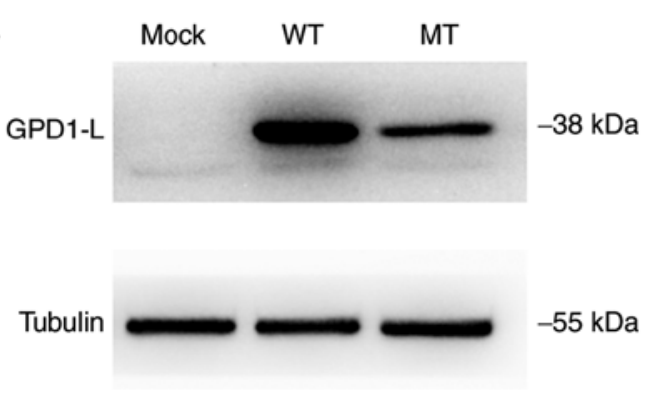

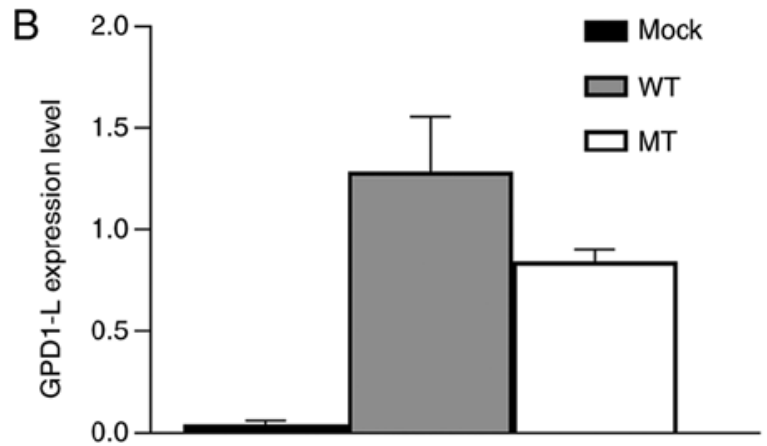

Figure 2. Expression of WT and MT GPD1-L proteins. (A) The GPD1-L protein is the blot located at the molecular weight of $38 \mathrm{kD}$. The three blots from left to right represent the blank, WT and MT groups, respectively. (B) Grayscale analysis found that the GPD1-L protein was almost not expressed in the blank group. Both the WT and MT groups expressed GPD1-L protein. An analysis using Image J software indicated that the protein expression level of GPD1-L was significantly higher in the WT group compared with the MT group (P<0.01). GPD1-L, glycerol-3-phosphate dehydrogenase 1-like; WT, wild-type; MT, mutant type.
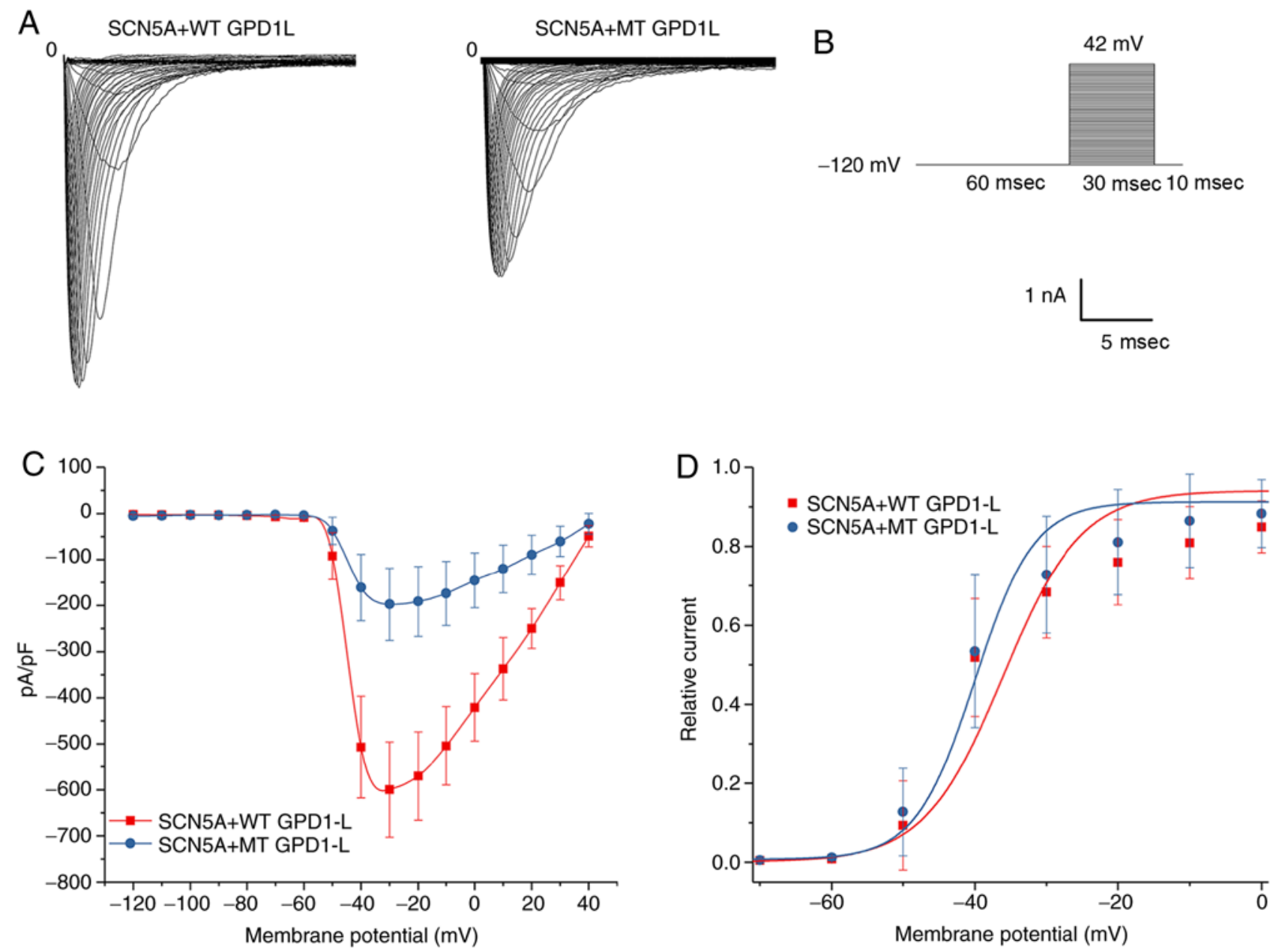

Figure 3. Activation of $\mathrm{I}_{\mathrm{Na}}$ in 293 cells co-transfected with both SCN5A and WT/MT GPD1-L plasmids. (A) Representative activation $\mathrm{I}_{\mathrm{Na}}$ traces of two groups induced using the voltage protocol. (B) Voltage protocol for activation. (C) $\mathrm{I}_{\mathrm{Na}}-\mathrm{V}$ activation relationship in the WT and MT groups, with $\mathrm{I}_{\mathrm{Na}}$ normalized to the cell membrane capacitance. The $\mathrm{I}_{\mathrm{Na}}$ density was significantly greater in the WT group compared with the MT group in the test potential range of -60 to $20 \mathrm{mV}(\mathrm{P}<0.05)$. The mean \pm standard deviation membrane capacitance values were $11.96 \pm 2.84$ and $11.47 \pm 3.70 \mathrm{pF}$ for the WT and MT groups, respectively $(P>0.05)$. (D) Voltage dependence of activation: $T h e V_{1 / 2}$ and slope factor $k$ values were $-39.15 \pm 4.80$ and $7.28 \pm 2.44 \mathrm{mV}$, respectively, for the $\mathrm{WT}$ group ( $\mathrm{n}=9$ ), and $-39.37 \pm 5.34$ and $7.05 \pm 2.55 \mathrm{mV}$, respectively, for the MT group $(\mathrm{n}=9)$. There were no significant differences in $\mathrm{V}_{1 / 2}$ or $\mathrm{k}$ between the WT and MT groups $(\mathrm{P}>0.05)$. GPD1-L, glycerol-3-phosphate dehydrogenase 1-like; WT, wild-type; MT, mutant type.

presented in Fig. 3B. The whole-cell patch-clamp recording experiment revealed that the maximum current densities for the WT and MT groups were $-599.50 \pm 103.80 \mathrm{pA} / \mathrm{pF}(\mathrm{n}=9)$ and $-197.25 \pm 78.53 \mathrm{pA} / \mathrm{pF}(\mathrm{n}=9)$, respectively (Fig. 3C). The
P112L mutation reduced the current by $~ 60 \%$ compared with the WT group $(\mathrm{P}<0.01)$. The IV curve morphology was basically the same between the two groups. The Boltzmann function was used to obtain the $V_{1 / 2}$ and slope factor $k$ 

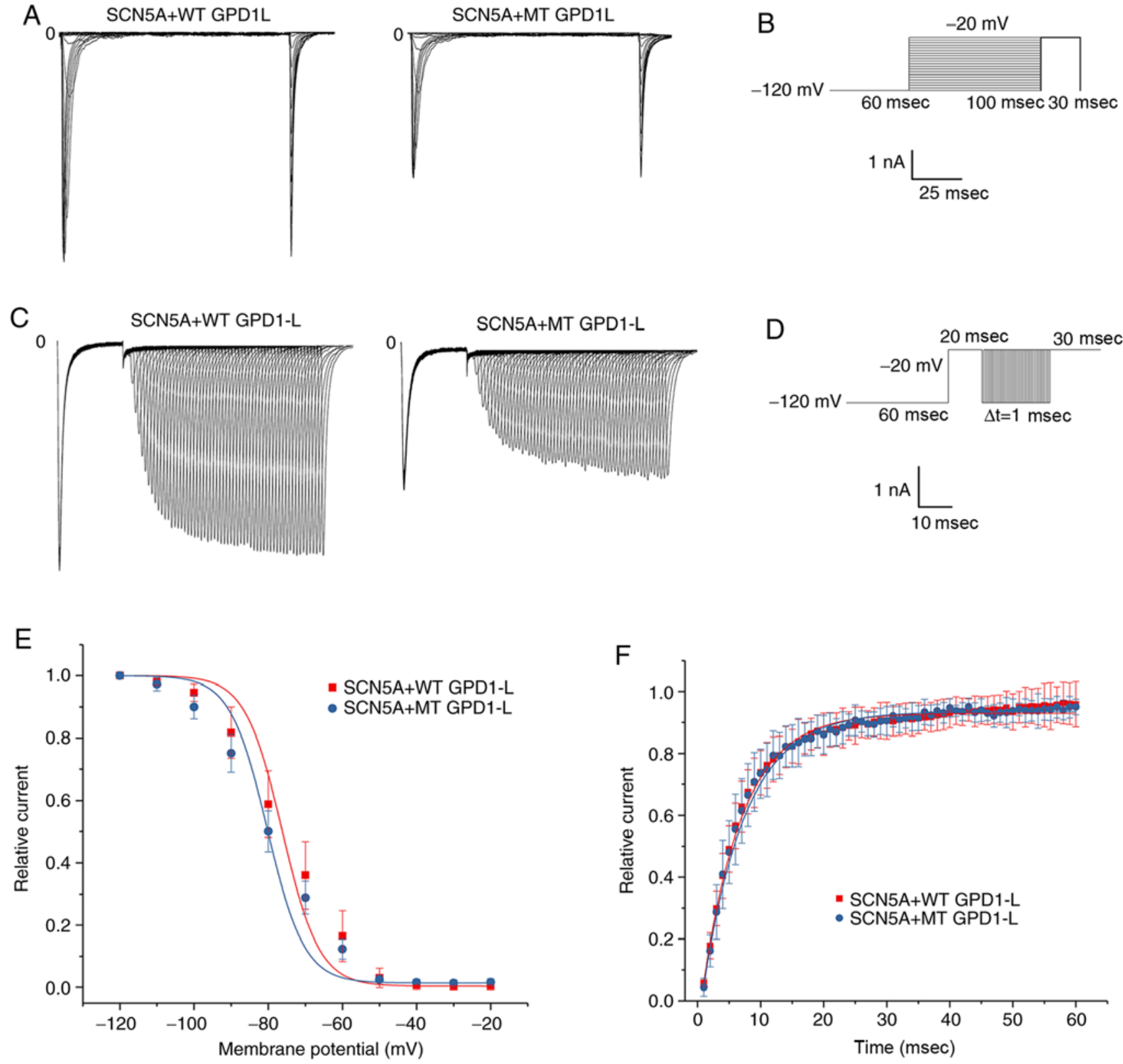

Figure 4. Inactivation and recovery of $\mathrm{I}_{\mathrm{Na}}$ in 293 cells co-transfected with both SCN5A and WT/MT GPD1-L plasmids. (A) Representative inactivation $\mathrm{I}_{\mathrm{Na}}$ trace of two groups induced using the voltage protocol. (B) Voltage protocol for inactivation. (C) Representative recovery $\mathrm{I}_{\mathrm{Na}}$ traces for the two groups. (D) Voltage protocol for recovery. (E) Voltage dependence of inactivation: The $\mathrm{V}_{1 / 2}$ and slope factor k values were $-75.97 \pm 4.58$ and $9.34 \pm 0.60 \mathrm{mV}$, respectively, for the WT group ( $=9$ ), and $-79.93 \pm 2.71$ and $9.71 \pm 0.65 \mathrm{mV}$, respectively, for the MT group ( $\mathrm{n}=9$ ). There were no significant differences in $\mathrm{V}_{1 / 2}$ or $\mathrm{k}$ between the WT and MT groups $(P>0.05)$. (F) Voltage dependence of recovery: $\tau$ was $6.26 \pm 0.86 \mathrm{msec}$ for the WT group $(\mathrm{n}=5)$ and $6.24 \pm 1.49 \mathrm{msec}$ for the MT group (n=5). There was no significant difference in $\tau$ between the WT and MT groups. GPD1-L, glycerol-3-phosphate dehydrogenase 1-like; WT, wild-type; MT, mutant type.

(Fig. 3D). The results indicated that the steady-activation curves for both groups began to activate at $\sim-60 \mathrm{mV}$. There were no significant between-group differences for $V_{1 / 2}$ $(\mathrm{P}=0.43)$ or slope factor $\mathrm{k}$ values $(\mathrm{P}=0.17)$. These results indicated that the mutation exerted little effect on activation of $\mathrm{I}_{\mathrm{Na}}$ (Table II). Representative results for inactivation and recovery of $\mathrm{I}_{\mathrm{Na}}$ and stimulation protocols are presented in Fig. 4A-D. The Boltzmann inactivation curve function was used to obtain the $\mathrm{V}_{1 / 2}$ and slope factor $\mathrm{k}$ (Fig. 4E). Compared with the WT group, a negative voltage change was detected in the MT group. There were no significant between-group differences in $\mathrm{V}_{1 / 2}(\mathrm{P}=0.54)$ or slope factor $\mathrm{k}$ values $(\mathrm{P}=0.38)$. These results indicated that the mutation exerted little effect on the inactivation of $\mathrm{I}_{\mathrm{Na}}$ (Table II). An exponential reactivation curve function was fitted to obtain the $\tau$ (Fig. 3F). The results indicated that the mutation exerted little effect on recovery of $\mathrm{I}_{\mathrm{Na}}(\mathrm{P}=0.77$; Table $\mathrm{II})$.

The P112L mutant reduces localization of GPDI-L adjacent to the cell surface. To investigate the effect of the P112L mutation on GPD1-L localization in cells, 293 cells were transfected with SCN5A plasmid and eGFP-WT/MT GPD1-L fusion plasmid (1:1 ratio). After a 48-h transfection period, the cells were treated for confocal microscopy observation. Dil was used to stain the cell membranes. The eGFP-GPD1-L fusion protein was used to track the localization of GPD1-L in 
Table II. Gating kinetics parameters of $\mathrm{I}_{\mathrm{Na}}$ in 293 cells co-expressed of SCN5A and WT/MT GPD1-L.

\begin{tabular}{|c|c|c|c|c|c|c|c|c|}
\hline \multirow[b]{2}{*}{ Groups } & \multicolumn{3}{|c|}{ Activation } & \multicolumn{3}{|c|}{ Inactivation } & \multicolumn{2}{|c|}{ Recovery } \\
\hline & $\mathrm{V}_{1 / 2}(\mathrm{mV})$ & $\mathrm{k}$ & $\mathrm{n}$ & $\mathrm{V}_{1 / 2}(\mathrm{mV})$ & $\mathrm{k}$ & $\mathrm{n}$ & $\tau(\mathrm{msec})$ & $\mathrm{n}$ \\
\hline SCN5A + WT GPD1-L & $-39.15 \pm 4.80$ & $7.28 \pm 2.44$ & 7 & $-75.97 \pm 4.58$ & $9.34 \pm 0.60$ & 9 & $6.26 \pm 0.86$ & 5 \\
\hline SCN5A + MT GPD1-L & $-39.37 \pm 5.34^{\mathrm{a}}$ & $7.05 \pm 2.55^{\mathrm{a}}$ & 7 & $-79.93 \pm 2.71^{\mathrm{a}}$ & $9.71 \pm 0.65^{\mathrm{a}}$ & 9 & $6.24 \pm 1.49^{\mathrm{a}}$ & 5 \\
\hline
\end{tabular}

${ }^{a} \mathrm{P}>0.05$ vs. WT. The results are expressed as mean \pm standard deviation. $\mathrm{V}_{1 / 2}$, voltage of half-maximally activated or inactivation; $\mathrm{k}$, slope factor; WT, wild-type; MT, mutant type.
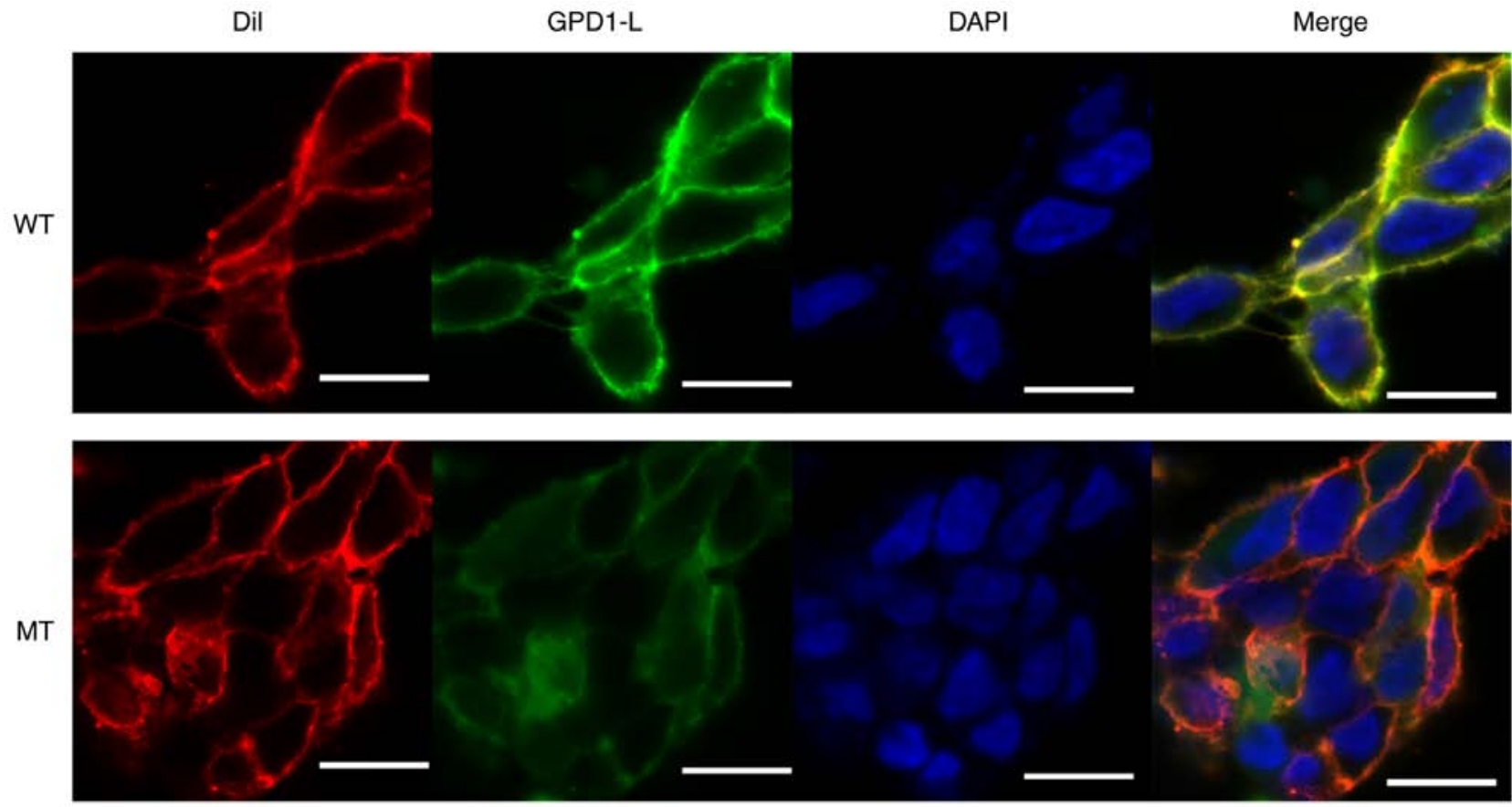

Figure 5. Distribution of WT and MT GPD1-L protein in 293 cells. 293 cells transfected with WT/MT eGFP-GPD1L were observed by confocal fluorescence microscopy. The red color indicates the plasma membrane marker Dil. The green color indicates the WT/MT eGFP-GPD1L fusion protein, which can track the localization of GPD1-L in 293 cells. The blue color indicates the cell nucleus marker DAPI. Merge imaging was shown to indicate the subcellular localization of WT/MT eGFP-GPD1L fusion protein. Both the WT and MT GPD1-L were mainly distributed in the cytoplasm. The nuclei displayed lower levels of GPD1-L. Near the membrane, the expression level of WT GPD1-L was higher compared with the MT group. Scale bar, 20 $\mu \mathrm{m}$. GPD1-L, glycerol-3-phosphate dehydrogenase 1-like; WT, wild-type; MT, mutant type.

the 293 cells. The results indicated that the expression levels of GPD1-L near the membrane were higher in the WT group compared with those in the MT group (Fig. 5). Both the WT and MT GPD1-L were mainly distributed in the cytoplasm, whereas the distribution in the nuclei was lower in both groups (Fig. 5).

\section{Discussion}

In the present study, the whole-cell patch-clamp recording experiment results indicated that, compared with the WT group, the activation of $\mathrm{I}_{\mathrm{Na}}$ was $60 \%$ lower in the MT group. The western blotting results indicated that GPD1-L was successfully transfected in 293 cells and the expression of the mutant GPD1-L protein was lower in the MT group. The evaluation using confocal microscopy revealed that the MT GPD1-L was less expressed near the cell membrane and more expressed in the cytoplasm.
Research on the mechanism of ERS and severe ventricular arrhythmia has reached the ion level (18). The change in the action potential notch of the epicardial membrane is related to the $\mathbf{J}$ wave, and the increase in repolarization current (secondary to the decrease in inward current or the increase in outward current) leads to an increase in the $\mathrm{J}$ waves or elevation of ST segments (19). The gene mutation leading to the morphological change in the action potential notch may result in the formation of ERPs. Currently, the genetic variations associated with both ERP and ERS include seven types: KCNJ8 (9) and ABCC9 (15), which regulate pore formation of the $\mathrm{I}_{\mathrm{K}}$-ATP channel and the ATP-sensitive subunit; CACNA1C (11), CACNB2b (12), CACNA2D1 (12), and related subunits of the L-type calcium channel; and SCN5A (20) and SCN10A (13) of the $I_{\mathrm{Na}}$ channel. The enhanced repolarization dispersion is prone to form 2-phase reentry, which may result in premature ventricular contractions and ventricular tachycardia (19). 
GPD1-L, a glycerol-3-phosphate dehydrogenase 1-like gene, plays an important role in the function regulation of myocardial sodium channels; it is an important susceptibility gene for sudden unexpected death syndrome (21), sudden infant death syndrome (21), and Brugada syndrome (22). The human GPD1-L gene is located on chromosome 3 and encodes a protein composed of 351 amino acids. GPD1-L may interact with proteins associated with ion channels, such as ankyrin- $\mathrm{G}$, syntrophin, caveolin-3 and Nedd4-2 (23). GPD1-L regulates endoplasmic reticulum signaling by affecting the protein kinase A-dependent phosphorylation (24). GPD1-L also affects the oxidative state to regulate the function of cardiac sodium channels (16).

The first reported association for GPD1-L was in type II Brugada syndrome (25), where it is co-expressed with Nav1.5 in the cardiomyocytes. Van Norstrand (21) detected three mutation sites for GPD1-L (E83K, I124V and R273C) in 83 cases of sudden unexpected death syndrome and in 221 cases of subsequent sudden infant death syndrome. All sites were highly conserved, and none were detected in the 300 control group patients. Experiments with 293 cells and neonatal rat myocardial cells transfected with the aforementioned mutants demonstrated that the mutants may cause an instantaneous decrease in sodium current density (21).

We found that the activation current density of the MT group decreased by $60 \%$ compared with the WT group. A recent study found that GPD1-L is expressed near the cell membrane (26) and can regulate the redox state of sodium channels via PKC-dependent phosphorylation, thus affecting the function of sodium channels (16). It was inferred that the decrease in the activation of $\mathrm{I}_{\mathrm{Na}}$ can increase the relative inward current of the action potential during repolarization through the mechanisms mentioned above and, thus, alter the notch morphology of action potentials in myocardial cells and form $\mathbf{J}$ waves and $\mathbf{J}$-point elevations in the electrocardiogram. Further study is required to confirm the effects of GPD1-L P112L on action potentials and elucidate the exact mechanisms underlying the association between GPD1-L and sodium channels. The western blotting results indicated that the mutation decreased the total expression of GPD1-L. Although confocal microscopic observation found that GPD1-L somewhat co-located with cell membrane markers, a previous study demonstrated that GPD1-L is localized near rather than on the cell membrane (26). Therefore, the results may be interpreted as follows: MT GPD1-L was less expressed near the cell membrane and more expressed in the cytoplasm compared with WT GPD1-L. Our results indicate that the difference in total expression level and distribution of GPD1-L caused by mutations may also be implicated in the occurrence of ERS. Further research is required to investigate the mechanisms of expression and abnormal intracellular transport of GPD1-L affected by mutations.

In summary, it was herein demonstrated that GPD1-L P112L decreased the activation of $\mathrm{I}_{\mathrm{Na}}$. The decreased total cell GPD1-L expression and the decreased expression of GPD1-L near the cell membrane may also contribute to the development of abnormal sodium currents. Our study results suggested that GPD1-L P112L may be a novel pathogenic genetic mutation of ERS.

\section{Acknowledgements}

Not applicable.

\section{Funding}

This study was supported by the National Natural Science Foundation of China (grant nos. 81370285 and 81970206), and the Guangzhou City Science and Technology Program (grant no. 201508020057).

\section{Availability of data and materials}

The datasets generated and/or analyzed during the present study are available from the corresponding author on reasonable request.

\section{Authors' contributions}

WSH and JF made substantial contributions to the design of the present study. JF, JCC, YH, CYJ, CXM and ZZH performed the experiments; JF, JCC, YH, CYJ, CXM and ZZH analyzed the data; JF, WSH, JCC, CYJ wrote the manuscript. All authors have read and approved the final version of the manuscript.

\section{Ethics approval and consent to participate}

The investigation was approved by the Ethics Committee of the First Affiliated Hospital of Sun Yat-Sen University. All family members agreed to participate in the study and signed the informed consent forms.

\section{Patient consent for publication}

All patients provided written informed consent regarding the publication of their data, including clinical and genetic information.

\section{Competing interests}

All the authors declare that they have no competing interests.

\section{References}

1. Tikkanen JT, Anttonen O, Junttila MJ, Aro AL, Kerola T, Rissanen HA, Reunanen A and Huikuri HV: Long-term outcome associated with early repolarization on electrocardiography. N Engl J Med 361: 2529-2537, 2009.

2. Junttila MJ, Tikkanen JT, Kenttä T, Anttonen O, Aro AL, Porthan K, Kerola T, Rissanen HA, Knekt P and Huikuri HV: Early repolarization as a predictor of arrhythmic and nonarrhythmic cardiac events in middle-aged subjects. Heart Rhythm 11: 1701-1706, 2014.

3. Tang Y, Stahl-Herz J and Sampson BA: Molecular diagnostics of cardiovascular diseases in sudden unexplained death. Cardiovasc Pathol 23: 1-4, 2014.

4. Gourraud JB, Le Scouarnec S, Sacher F, Chatel S, Derval N, Portero V, Chavernac P, Sandoval JE, Mabo P, Redon R, et al: Identification of large families in early repolarization syndrome. J Am Coll Cardiol 61: 164-172, 2013.

5. McCorquodale A, Poulton R, Hendry J, Norrish G, Field E, Mead-Regan S, Lowe M and Kaski JP: High prevalence of early repolarization in the paediatric relatives of sudden arrhythmic death syndrome victims and in normal controls. Europace 19: 1385-1391, 2017. 
6. Koncz I, Gurabi Z, Patocskai B, Panama BK, Szél T, Hu D, Barajas-Martinez $\mathrm{H}$ and Antzelevitch C: Mechanisms underlying the development of the electrocardiographic and arrhythmic manifestations of early repolarization syndrome. J Mol Cell Cardiol 68: 20-28, 2014.

7. Chauveau S, Janin A, Till M, Morel E, Chevalier P and Millat G: Early repolarization syndrome caused by de novo duplication of KCND3 detected by next-generation sequencing. Heart Rhythm Case Rep 3: 574-578, 2017.

8. Watanabe H, Ohkubo K, Watanabe I, Matsuyama TA, Ishibashi-Ueda H, Yagihara N, Shimizu W, Horie M, Minamino T and Makita N: SCN5A mutation associated with ventricular fibrillation, early repolarization, and concealed myocardial abnormalities. Int J Cardiol 165: e21-e23, 2013.

9. Medeiros-Domingo A, Tan BH, Crotti L, Tester DJ, Eckhardt L, Cuoretti A, Kroboth SL, Song C, Zhou Q, Kopp D, et al: Gain-of-function mutation S422L in the KCNJ8-encoded cardiac K(ATP) channel Kir6.1 as a pathogenic substrate for J-wave syndromes. Heart Rhythm 7: 1466-1471, 2010.

10. Liu X, Shen Y, Xie J, Bao H, Cao Q, Wan R, Xu X, Zhou H, Huang L, Xu Z, et al: A mutation in the CACNA1C gene leads to early repolarization syndrome with incomplete penetrance: A Chinese family study. PLoS One 12: e177532, 2017.

11. Chen Y, Barajas-Martinez H, Zhu D, Wang X, Chen C, Zhuang R, Shi J, Wu X, Tao Y, Jin W, et al: Novel trigenic CACNA1C/DES/MYPN mutations in a family of hypertrophic cardiomyopathy with early repolarization and short QT syndrome. J Transl Med 15: 78, 2017.

12. Burashnikov E, Pfeiffer R, Barajas-Martinez H, Delpón E, Hu D, Desai M, Borggrefe M, Häissaguerre M, Kanter R, Pollevick GD, et al: Mutations in the cardiac L-type calcium channel associated with inherited J-wave syndromes and sudden cardiac death. Heart Rhythm 7: 1872-1882, 2010.

13. Di Stolfo G, Palumbo P, Castellana S, Mastroianno S, Biagini T, Palumbo O, Leone MP, De Luca G, Potenza DR, Mazza T, et al: Sudden cardiac death in J wave syndrome with short QT associated to a novel mutation in Nav 1.8 coding gene SCN10A: First case report for a possible pharmacogenomic role. J Electrocardiol 51 809-813, 2018

14. Delaney JT, Muhammad R, Blair MA, Kor K, Fish FA, Roden DM and Darbar D: A KCNJ8 mutation associated with early repolarization and atrial fibrillation. Europace 14: 1428-1432, 2012.

15. Hu D, Barajas-Martinez H, Terzic A, Park S, Pfeiffer R Burashnikov E, Wu Y,Borggrefe M, Veltmann C, Schimpf R, et al: ABCC9 is a novel Brugada and early repolarization syndrome susceptibility gene. Int J Cardiol 171: 431-442, 2014.
16. Valdivia CR, Ueda K, Ackerman MJ and Makielski JC: GPD1L links redox state to cardiac excitability by PKC-dependent phosphorylation of the sodium channel SCN5A. Am J Physiol Heart Circ Physiol 297: H1446-H1452, 2009.

17. Huang H, Chen YQ, Fan LL, Guo S, Li JJ, Jin JY and Xiang R: Whole-exome sequencing identifies a novel mutation of GPD1L (R189X) associated with familial conduction disease and sudden death. J Cell Mol Med 22: 1350-1354, 2018

18. Barbosa EC, Bomfim Ade S, Benchimol-Barbosa PR and Ginefra P: Ionic mechanisms and vectorial model of early repolarization pattern in the surface electrocardiogram of the athlete. Ann Noninvasive Electrocardiol 13: 301-307, 2008.

19. Antzelevitch C: Genetic, molecular and cellular mechanisms underlying the J wave syndromes. Circ J 76: 1054-1065, 2012

20. Guo Q, Ren L, Chen X, Hou C, Chu J, Pu J and Zhang S: A novel mutation in the SCN5A gene contributes to arrhythmogenic characteristics of early repolarization syndrome. Int J Mol Med 37: 727-733, 2016.

21. Van Norstrand DW, Valdivia CR, Tester DJ, Ueda K, London B, Makielski JC and Ackerman MJ: Molecular and functional characterization of novel glycerol-3-phosphate dehydrogenase 1 like gene (GPD1-L) mutations in sudden infant death syndrome. Circulation 116: 2253-2259, 2007.

22. Makiyama T, Akao M, Haruna Y, Tsuji K, Doi T, Ohno S, Nishio Y, Kita T and Horie M: Mutation analysis of the glycerol-3 phosphate dehydrogenase-1 like (GPD1L) gene in Japanese patients with brugada syndrome. Circ J 72: 1705-1706, 2008.

23. Abriel $\mathrm{H}$ and Kass RS: Regulation of the voltage-gated cardiac sodium channel Nav1.5 by interacting proteins. Trends Cardiovasc Med 15: 35-40, 2005.

24. Hallaq H, Yang Z, Viswanathan PC, Fukuda K, Shen W, Wang DW, Wells KS, Zhou J, Yi J and Murray KT: Quantitation of protein kinase A-mediated trafficking of cardiac sodium channels in living cells. Cardiovasc Res 72: 250-261, 2006.

25. Weiss R, Barmada MM, Nguyen T, Seibel JS, Cavlovich D, Kornblit CA, Angelilli A, Villanueva F, McNamara DM and London B: Clinical and molecular heterogeneity in the brugada syndrome: A novel gene locus on chromosome 3. Circulation 105: 707-713, 2002

26. London B, Michalec M, Mehdi H, Zhu X, Kerchner L, Sanyal S, Viswanathan PC, Pfahnl AE, Shang LL, Madhusudanan M, et al: Mutation in glycerol-3-phosphate dehydrogenase 1 like gene (GPD1-L) decreases cardiac Na+ current and causes inherited arrhythmias. Circulation 116: 2260-2268, 2007. 